\title{
BMJ Open Use of novel psychoactive substances by inpatients on general adult psychiatric wards
}

\author{
Jack L Stanley, ${ }^{1}$ Daniel V Mogford, ${ }^{2}$ Rebecca J Lawrence, ${ }^{2}$ Stephen M Lawrie ${ }^{3}$
}

To cite: Stanley JL, Mogford DV, Lawrence RJ, et al. Use of novel psychoactive substances by inpatients on general adult psychiatric wards. BMJ Open 2016;6:e009430.

doi:10.1136/bmjopen-2015009430

- Prepublication history and additional material is available. To view please visit the journal (http://dx.doi.org/ 10.1136/bmjopen-2015009430).

Received 24 July 2015 Revised 5 November 2015 Accepted 27 November 2015

CrossMark

\footnotetext{
${ }^{1}$ Undergraduate- 5 th year, University of Edinburgh, Edinburgh, UK

${ }^{2}$ Department of Psychiatry, NHS Lothian, Edinburgh, UK ${ }^{3}$ University of Edinburgh, Edinburgh, UK
}

\section{Correspondence to}

Dr Rebecca J Lawrence; rebecca.lawrence@nhslothian. scot.nhs.uk

\section{ABSTRACT}

Objectives: Non-illicit alternatives to controlled drugs, known as novel psychoactive substances (NPS), have recently risen to prominence. They are readily available, with uncertain pharmacology and no widely available assay. Given that psychiatric patients are at risk of comorbid substance abuse, we hypothesised that NPS use would be present in the psychiatric population, and sought to determine its prevalence and investigate the characteristics of those who use these drugs with a retrospective review of discharge letters.

Setting: General adult inpatient wards of a psychiatric hospital in a Scottish city.

Participants: All adult inpatients (18-65) discharged from general psychiatric wards between 1 July 2014 and 31 December 2014. Of the 483 admissions identified, 46 were admissions for maintenance electroconvulsive therapy (ECT) and were excluded. Of the remaining 437 admissions, 49 discharge letters were unobtainable, leaving 388 admissions to analyse.

Primary outcome measure: The mention, or lack thereof, of NPS use in discharge letters was our planned primary outcome measure and was also the primary outcome measure we used in our analysis.

Results: NPS use was identified in $22.2 \%$ of admissions, contributing to psychiatric symptoms in $59.3 \%$. In comparison to non-users, NPS users were younger $(p<0.01)$, male and more likely to have a forensic history $((p<0.001)$ for both). The diagnosis of drug-induced psychosis was significantly more likely in NPS users ( $p<0.001$, OR 18.7, 95\% Cl 8.1 to 43.0) and the diagnosis of depression was significantly less likely ( $p<0.005,0 R 0.133, C l 0.031$ to 0.558 ). Use of cannabis was significantly more likely in NPS users $(p<0.001,0 R 4.2, \mathrm{Cl} 2.5$ to 7.1$)$, as was substitute opiate prescribing ( $p<0.001,0 \mathrm{R} 3.7, \mathrm{Cl} 1.8$ to 7.4 ).

Conclusions: NPS use was prevalent among young, male psychiatric inpatients, in particular those with drug-induced psychosis and often occurred alongside illicit drug use.

\section{INTRODUCTION}

\section{Background}

Illicit drug use has long been recognised as a public health concern in Scotland and the rest of the UK, with 2013 survey data

\section{Strengths and limitations of this study}

- We provide estimates of the prevalence and potential clinical relevance of novel psychoactive substance (NPS) use in recently discharged psychiatric inpatients.

- We have demonstrated several statistically significant relationships regarding the demographics of psychiatric inpatients who use NPS.

- We cannot infer causal relationships from our results.

- We relied on discharge letters, potentially introducing reporting bias.

- Our results refer to NPS as a uniform group, when in fact they are a heterogeneous group of psychoactive substances, which are likely to be used by differing groups of psychiatric inpatients.

suggesting that $6.2 \%$ of adults had used drugs in the last year. ${ }^{1}$ This rate has been falling year-on-year since the 2008/2009 survey. However, in recent years, new classes of drugs with structures not controlled under the law have emerged, in addition to the 'classic' drugs of abuse. They are known as novel psychoactive substances (NPS) and their alleged non-illicit status has led the media to label them as 'legal highs'.

NPS are defined by the UK Advisory Council on the Misuse of Drugs as "psychoactive drugs which are not prohibited by the United Nations Single Convention on Narcotic Drugs or by the Misuse of Drugs Act 1971, and which people are seeking for intoxicant use". ${ }^{2}$ The blanket terminology of 'NPS' covers six distinct groups: synthetic cannabinoids, phenethylamines, cathinones, plant-based substances, piperazines and ketamine. Since the rapid and well-publicised surge in mephedrone use in $2009,{ }^{3}$ the emergence of NPS as drugs of abuse has represented a new challenge both to lawmakers and healthcare workers.

The total number of NPS reported to the United Nations Office on Drugs and Crime 
(UNODC) stood at 348 in December 2013, a large increase on the 251 documented in July 2012, ${ }^{4}$ illustrating the growing nature of the problem. Their popularity stems largely from their ready availability online and in shops $^{5}$ and their alleged non-illicit status. ${ }^{6}$ The point that their legality does not equate with safety has been made many times. ${ }^{7}$ They are often synthesised by modifying the structure of controlled drugs and, as such, discovery of new substances is hypothesised to be a continuous phenomenon, ${ }^{6}$ with current estimates suggesting that on average one new NPS is made available online in the European Union every week. ${ }^{5}$ The time lag between their recognition by policymakers and becoming controlled means that their consumption is unlikely to be diminished under current legislation; however, the announcement of the Psychoactive Substances Bill in May 2015 may lead to changes in availability, given its implications for their future legal status. ${ }^{8}$

NPS supply is unregulated, and, as such, there is significant variation in content between substances which are labelled as being the same. ${ }^{9}$ This variety, coupled with the heterogeneous pharmacology of these substances, makes characterising their effects problematic. As such it is unsurprising that they have unpredictable toxicological and psychiatric effects, ${ }^{10}$ with documented cases of psychosis, ${ }^{11}$ poisoning ${ }^{12}$ and death. ${ }^{13}$

Psychiatric patients have an increased rate of comorbid substance abuse compared with the general population, ${ }^{14}$ and recent studies show that the same trend is true of NPS use. $^{15}$ Evidence suggests that psychiatric patients with comorbid substance abuse have poorer clinical outcomes, cost health services more ${ }^{16}$ and have an increased number of psychiatric admissions ${ }^{17}$ than those without. Furthermore, it has been suggested that drug use can precipitate the emergence of psychiatric symptoms in at-risk individuals, ${ }^{18}$ and, from case reports, it appears that NPS use has been implicated in the emergence of psychotic symptoms. ${ }^{11}$ A study published in 2013 showed that $13 \%$ of patients attending mental health services were using head shop drugs (a term commonly used to refer to NPS), with $54 \%$ reporting adverse effects on their mental health. ${ }^{19}$ It is likely that psychiatric services will encounter many of the consequences of increasing NPS use.

The relative novelty of NPS as substances of abuse, and the rapid fluctuations in the popularity of individual substances, mean that they currently have a limited evidence base, with the recent Novel Psychoactive Treatment UK Network (Neptune) ${ }^{20}$ report representing the first cohesive attempt in the UK to collate knowledge and propose management approaches on the issue. NPS use by psychiatric patients and the role it plays in psychiatric inpatient admission has even less evidence, prompting our current attempt at its characterisation.

\section{Objectives}

We hypothesised that NPS use would be present in a proportion of admissions to general adult psychiatric wards in Edinburgh. Our aims were to quantify the proportion of inpatient admissions which involved NPS use, and then to characterise the group of NPS users, in comparison with the non-NPS using patients. We used a retrospective case note review approach to maximise the included population. We looked for differences in demographics, mental health diagnosis, use of Mental Health Act, length of admission, forensic history and comorbidity with other substance misuse. We also sought to identify patterns of use by recording the substance being used and route of administration where this information was available.

\section{METHODS}

\section{Study design and setting}

This was a cross-sectional survey conducted as a retrospective review of electronic discharge letters for all patients discharged from general adult psychiatric wards in the Royal Edinburgh Hospital, a large urban psychiatric hospital, between 1 July 2014 and 31 December 2014.

\section{Participants}

Four hundred and eighty-three admissions were identified using the electronic patient record system. The duration of 6 months was chosen to provide an accurate representation of the population within the time constraints available.

\section{Data collection}

The data collection was carried out by a fourth year undergraduate medical student at Edinburgh University. Of the 483 admissions identified, 46 were admissions for maintenance electroconvulsive therapy (ECT) and were excluded. Of the remaining 437 admissions, 49 discharge letters were unobtainable, leaving 388 admissions to analyse (representing $88.8 \%$ of the identified admissions).

In 13 of these 388 admissions, the discharge letter covered 2 separate admissions for the same patient in a short space of time. The information was coded twice, for each date of admission, to give a fair representation of service access.

Data from these 388 admissions were recorded using the collection tool detailed in online supplementary file 1 . Information not included on the letter was coded as 'not available', and this applied particularly to 'substance use', 'forensic history' and 'custodial sentence'. The patient's age reflects their age at admission, and the primary diagnosis reflects that stated on the discharge letter, meaning it is likely to correspond to the diagnosis relevant to admission. Mention of illicit substance use at any level was recorded as a positive finding, with the exception of alcohol, which was recorded only when the discharge letter suggested harmful use, either explicitly or with reference to consumption in line with the International Classification of Diseases, 10th Edition (ICD-10) diagnosis of harmful use or alcohol dependence. 
When recording NPS use, we adopted a definition based on those used by the European Monitoring Centre for Drugs and Drug Addiction (EMCDDA) ${ }^{5}$ and Neptune, ${ }^{20}$ defining them as a group of psychoactive compounds that emerged as alternatives to those controlled by the United Nations conventions, which may pose a public health threat comparable to that posed by substances listed in these conventions. ${ }^{5}$ Some of these substances are now subject to legal control in the UK; however, the term 'legal high' in discharge letters was deemed as evidence of NPS use given the widespread use of the term in reference to substances classified as NPS by patients and healthcare workers. ${ }^{21}$ Owing to a lack of information regarding the constituents of many substances, they were subdivided into cannabinoids and stimulants, as opposed to the more stringent groups detailed in the introduction.

\section{Statistical methods}

IBM SPSS Statistics V.22.0.0.1 was used for statistical analysis. The $\chi^{2}$ test was used to compare differences with regard to gender, primary diagnosis, substance use, forensic history, custodial sentence and use of the Mental Health Act. Fisher's exact test was used to calculate ORs. Student's t test was used to assess differences in length of stay and age.

\section{RESULTS}

Figure 1 details the prevalence of NPS use, including characterisation of individual NPS into stimulant or cannabinoid subtypes. Intravenous (IV) use was only noted for stimulants, and the rates are included due to the importance of IV use as a public health concern. NPS use was noted in $22.2 \%(\mathrm{n}=86)$ of discharge letters, with $59.3 \%(\mathrm{n}=51)$ of these stating that NPS use had

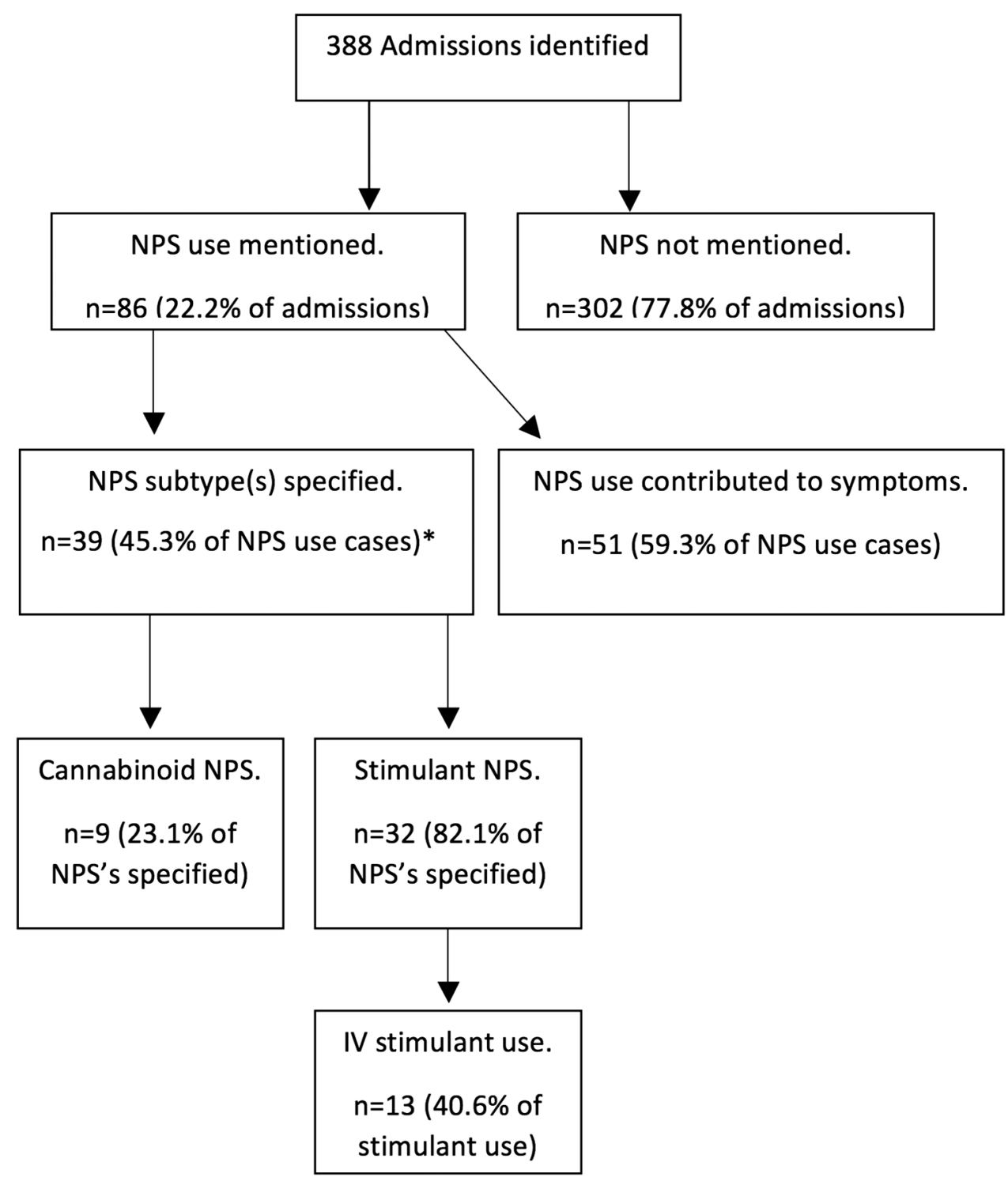

Figure 1 NPS prevalence. *n (NPS subtype) less than n (cannabinoid) and n (stimulant) combined due to poly NPS use. See online supplementary file 2 for breakdown of individual NPS frequency. IV, intravenous; NPS, novel psychoactive substance. 
contributed to the development of psychiatric symptoms relevant to the admission.

Table 1 details the demographic characteristics of NPS users and non-NPS users. There was a higher prevalence of males in the NPS users $(69.8 \%)$ than the non-NPS users group $(43.7 \%)$. This difference was shown to be statistically significant $(p<0.001)$, with males more likely to be NPS users than females (OR=2.9; 95\% CI 1.7 to 4.8$)$.

The data for employment and home circumstances did not show any statistically significant difference. NPS users were significantly more likely to have a forensic history $(\mathrm{p}<0.001, \mathrm{OR}=3.2$; 95\% CI 2.0 to 5.3$)$ and previous custodial sentences $(\mathrm{p}<0.001, \mathrm{OR}=5.0$; CI 2.6 to 9.3$)$ than non-NPS users. There was no statistically significant difference between rates of detention under the Mental Health Act.

Figure 2 shows that there was no statistically significant difference between the length of stay for those who used NPS and those who did not.

Figure 3 illustrates the primary diagnoses of NPS users and non-NPS users. The diagnosis of drug-induced psychosis was significantly higher in NPS users, with 29 cases where NPS use was documented and 8 where it was not $(\mathrm{p}<0.001, \mathrm{OR}=18.7 ; 95 \%$ CI 8.1 to 43.0$)$. Conversely, the prevalence of depression was significantly lower in NPS users, with 2 cases where NPS use was documented and 46 where it was not $(\mathrm{p}<0.005$, $\mathrm{OR}=0.133 ; 95 \%$ CI 0.031 to 0.558 ).

Figure 4 shows substance use (other than NPS) by NPS users and non-NPS users. NPS users had a higher incidence of use of all substances except benzodiazepines and gamma butyrolactone (GBL). This difference was statistically significant for cannabis $(\mathrm{p}<0.001, \mathrm{OR}=4.2$; $95 \%$ CI 2.5 to 7.1$)$ and substitute opioid use $(\mathrm{p}<0.001$, $\mathrm{OR}=3.7 ; 95 \%$ CI 1.8 to 7.4 ). Of the 86 admissions with documented NPS use, 20 had no other documented comorbid substance abuse.

\section{DISCUSSION}

We hypothesised that NPS use would be present in psychiatric admissions and found that $22.2 \%$ of discharge letters over a 6-month period identified NPS use. Furthermore, in $59.3 \%$ of cases of NPS use, it was suggested by the treating team that the NPS had contributed to the patient's psychiatric symptoms, although this cannot be proven by this study.

Our results also contribute to the emerging evidence regarding local NPS use. The discharges mentioned only stimulant NPS and synthetic cannabinoids. This is in line with findings by CREW 2000, ${ }^{22}$ whose survey suggested that 96\% of NPS use in Edinburgh fell into either of these two categories. Stimulant NPS use was identified in discharges more than three times as frequently as synthetic cannabinoid use. Cannabinoids have elsewhere been identified as the more common NPS subtype, with estimates suggesting that they account for $40 \%$ of NPS currently in circulation. This might suggest that either stimulants are more commonly used in Edinburgh, or that their use is more likely to precipitate psychiatric symptoms leading to admission.

Stimulant NPS use also carries the additional concern of IV administration. In our survey, the stimulant NPS 'Burst' was injected in $75 \%$ of cases where it was mentioned (see online supplementary file 2 for NPS subtype

Table 1 Demographic information for novel psychoactive substance (NPS) users and non-NPS users

\begin{tabular}{|c|c|c|c|c|}
\hline & $\begin{array}{l}\text { NPS users } \\
(n=86)\end{array}$ & Per cent & $\begin{array}{l}\text { Non-NPS users } \\
(n=302)\end{array}$ & Per cent \\
\hline Mean age (SD) & $36.1(9.4)^{\star}$ & & $42.5(12.5)^{\star}$ & \\
\hline \multicolumn{5}{|l|}{ Gender } \\
\hline Male & $60 \dagger$ & 69.8 & $132 \dagger$ & 43.7 \\
\hline Female & $26 \dagger$ & 30.2 & $165 \dagger$ & 54.6 \\
\hline Transgender & 0 & 0 & 5 & 1.7 \\
\hline \multicolumn{5}{|l|}{ Employment } \\
\hline Unemployed & 51 & 59.3 & 190 & 62.9 \\
\hline Student & 3 & 3.5 & 9 & 3 \\
\hline Employed & 5 & 5.8 & 49 & 16.2 \\
\hline Self-employed & 1 & 1.2 & 9 & 3 \\
\hline \multicolumn{5}{|l|}{ Home circumstances } \\
\hline Independent & 57 & 66.3 & 241 & 79.8 \\
\hline Supported & 10 & 11.6 & 25 & 8.3 \\
\hline Homeless & 12 & 14 & 27 & 8.9 \\
\hline Forensic history & $44 \dagger$ & 51.2 & $74 \dagger$ & 24.5 \\
\hline Previous custodial sentence & $25 \dagger$ & 29.1 & $23 \dagger$ & 7.6 \\
\hline Use of compulsory measures under mental health legislation & 30 & 34.9 & 105 & 34.8 \\
\hline \multicolumn{5}{|c|}{$\begin{array}{l}\text { Data missing for employment status in } 26 \text { NPS users and } 45 \text { non-NPS users. Data missing for home circumstances in seven NPS users and } \\
\text { nine non-NPS users. } \\
\text { *Denotes statistically significant difference between NPS users and non-NPS users ( } t \text { test) } p<0.01 \text {. } \\
\text { †Denotes statistically significant difference, between NPS users and non-NPS users }\left(\chi^{2}\right) p<0.001 . \\
\text { †Transgender data excluded from statistical analysis due to low numbers. }\end{array}$} \\
\hline
\end{tabular}




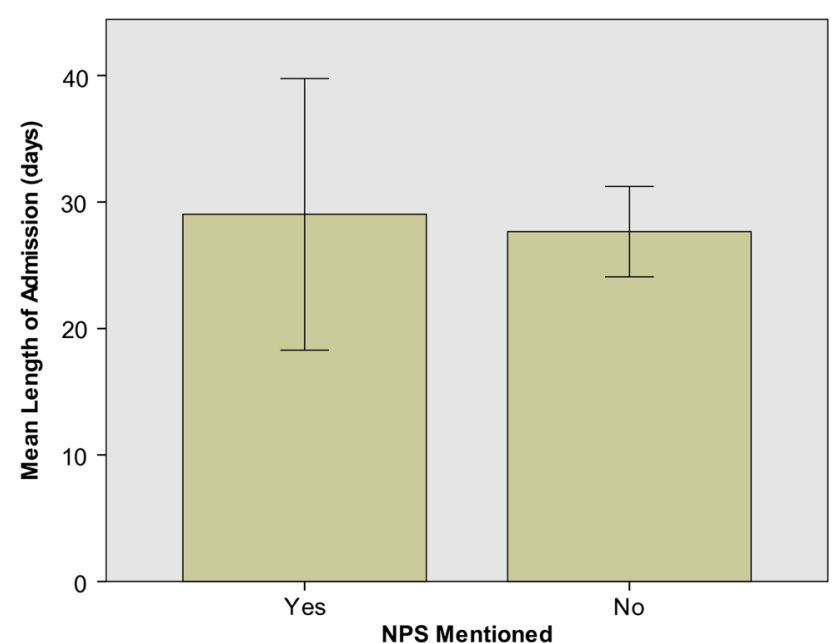

Figure 2 Mean length of admission for those who had, and had not, used NPS. NPS, novel psychoactive substance.

frequency). IV drug use has well-recognised public health implications. ${ }^{22}$ Additionally, when injecting stimulant NPS the effects are short lived, leading to more frequent injecting. Furthermore, many NPS contain microcrystalline cellulose, ${ }^{21}$ which does not dissolve, potentially leading to blocked veins and abscesses. Current estimates suggest that 'Burst' is injected in roughly $20 \%$ of users; ${ }^{22}$ however, our prevalence of $75 \%$ was much higher than this. This discrepancy may suggest that IV 'Burst' use could be more likely to

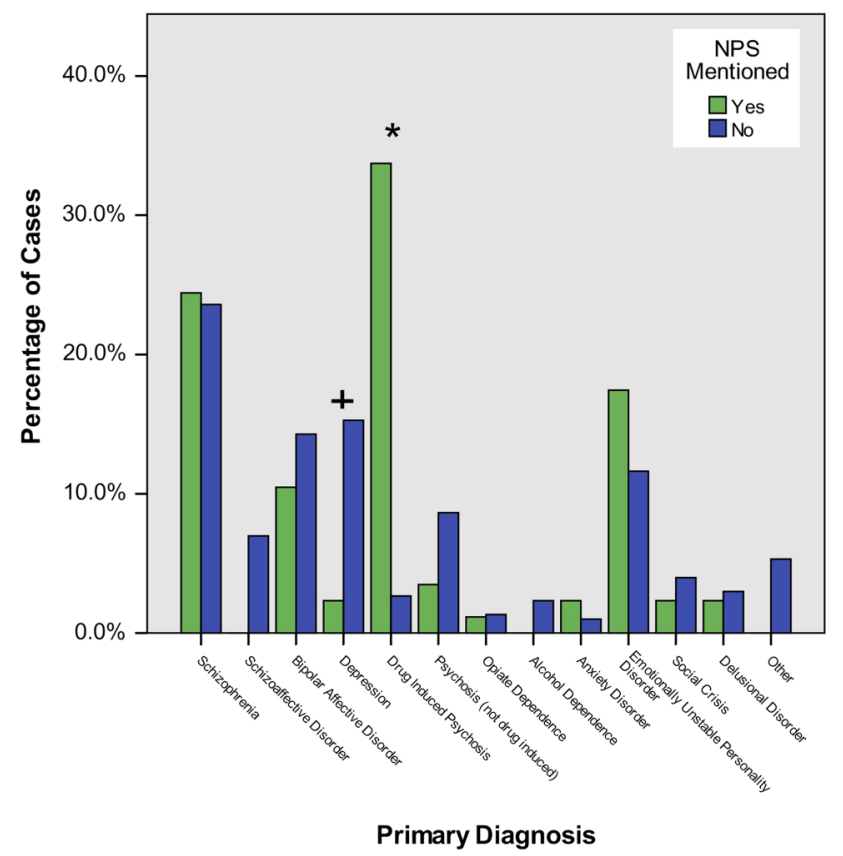

Figure 3 Primary diagnosis of those who had, and had not, used NPS. *Denotes statistically significant difference, between NPS users and non-NPS users $\left(\chi^{2}\right), p<0.001$. +Denotes statistically significant difference, between NPS users and non-NPS users $\left(\chi^{2}\right), p<0.005$. NPS, novel psychoactive substance.

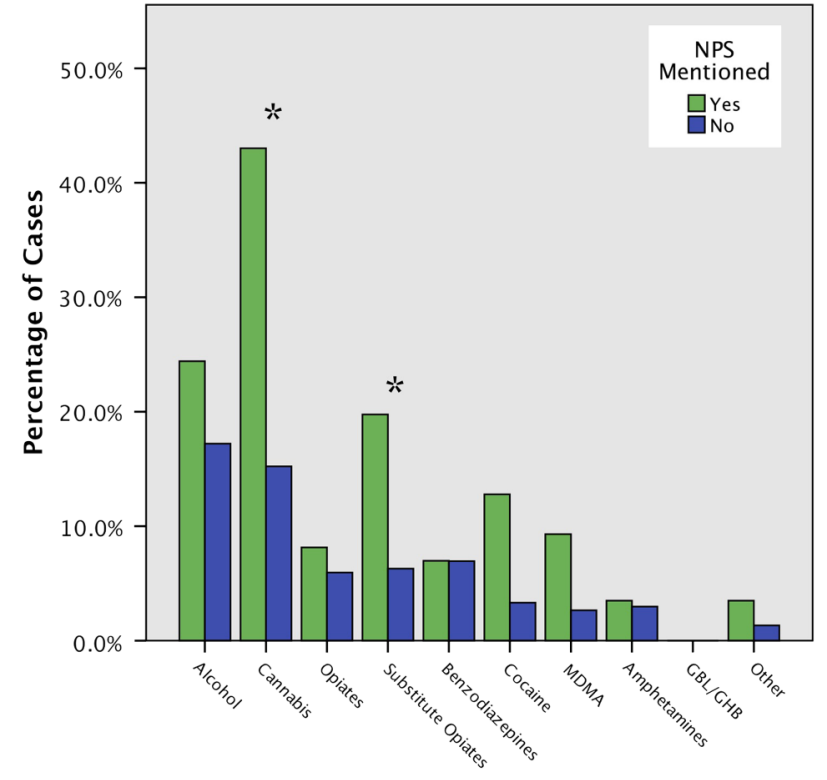

Substance Use

Figure 4 Alcohol and substance use of those who had, and had not, used NPS. *Denotes statistically significant difference, between NPS users and non-NPS users $\left(\chi^{2}\right), p<0.001$.

$\mathrm{GBL}$, gamma butyrolactone; GHB, gamma hydroxybutyrate; MDMA, 3,4-methylenedioxymethamphetamine (Ecstasy); NPS, novel psychoactive substance.

precipitate psychiatric symptoms than other routes of administration.

We found that NPS use was more common in younger males, which is in agreement with previously published findings which indicated a higher rate of head shop drug (NPS) use among those younger than 35 and among males. ${ }^{19}$ We also found that NPS users were more likely to have served a custodial sentence or have other forensic history in comparison to non-users. This follows previously documented trends in the use of controlled substances and alcohol by psychiatric patients. ${ }^{23}$ Homelessness is often noted as associated with substance abuse, although we did not detect a statistically significant difference in this respect.

Diagnostically, we found a statistically significant relationship between drug-induced psychosis and NPS use, as shown in figure 3, with a large OR, suggesting a strong association between the two variables (OR 18.7). It has been demonstrated that synthetic cannabinoids have a greater propensity to induce psychosis than cannabis, ${ }^{24}$ with reports of 'spiceophrenia' ('spice' being a form of synthetic cannabinoid) in the literature. ${ }^{25}$ Research has also demonstrated that synthetic cocaine has a longer half-life than its illicit derivative, ${ }^{26}$ and amphetamine type stimulants have been strongly associated with psychosis. ${ }^{27}$ Recent research has shown that over half of 'head shop drug' users attending adult mental health services reported adverse effects on their mental health, in many cases manifesting as symptoms of psychosis. ${ }^{19}$ In the context of previously published 
literature, our finding of an association between NPS use and drug-induced psychosis prompts the need for further investigation as a causal link cannot be inferred given the design of our study.

Figure 3 shows a negative association between depression and NPS use (OR 0.13), with very few instances of the two occurring together. There is extensive research linking depression with cannabis ${ }^{28}$ and alcohol ${ }^{29}$ consumption and this is therefore a curious result, particularly given that many NPS available are synthetic cannabinoids, with similar effects to cannabis. It may be the case that lack of motivation or limited social opportunities as a consequence of depression may be at the root of this phenomenon, or that people with depression preferentially use other drugs. This requires further research. It is also worth noting that those with documented NPS use include patients with multiple other diagnoses, such as schizophrenia and emotionally unstable personality disorder.

Despite the fact that NPS may be attractive due to their alleged non-illicit status, it has been shown that they are often added to a pre-existing repertoire of controlled substance use. ${ }^{30}$ We found a significantly higher rate of cannabis and substitute opiate use by NPS users in comparison to non-NPS users. NPS pharmacology is notoriously unpredictable, and this is likely to be exacerbated by polysubstance use. Psychiatric patients with multiple substance misuse disorders are shown to have higher rates of psychiatric comorbidity, ${ }^{18}$ and NPS use may be further exacerbating the problem. Although the nature of the association between cannabis use and psychosis is controversial, ${ }^{31}$ the high coexistence of NPS and cannabis use is of concern, particularly in light of the previously noted relationship between NPS use and drug-induced psychosis. Of note, 20 patients with documented NPS use had no documented comorbid substance use, which suggests that some NPS users may represent a different population to 'classic' drug users and that this may include otherwise drug-naive individuals.

NPS use was not shown to be related to an increased length of stay, or increased use of compulsory measures under mental health legislation, as shown in figure 2. This may be due to our small sample size; however, these two variables are likely to be multifactorial, and it is not surprising that their association with NPS use alone is not marked.

\section{Limitations and further work}

Our study had several limitations. The most significant of these was the fact that we relied on discharge letters to collect our data. Given the lack of widely available assays for the detection of NPS use, we were limited in our choice of study design. Relying on data recorded in discharge letters could have led to reporting bias (eg, NPS use may not have been included where it was not felt to be relevant, leading to possible under-reporting of NPS use). Knowledge of NPS is lacking in healthcare workers, with surveys among doctors showing a lack of confidence surrounding the subject. ${ }^{32}$ This is in keeping with the fact that in only 39 of the 86 letters where NPS use was identified was the NPS itself named. The discharge letters were not standardised, and therefore omissions and varying interpretations by the doctors writing them will have introduced a degree of bias. Similarly, when recording other substance use, we did not record toxicology screens, relying instead on what was written in the discharge letter, such that these data were also subject to reporting bias. The cross-sectional nature of our data collection meant that we were unable to infer causal relationships.

Our sample size was small and further subdivision by diagnosis and comorbid substance use resulted in smaller subgroups, meaning that the statistical values demonstrated should be interpreted with caution. Furthermore, we could not include data for the 49 unavailable discharge letters, leading to an incomplete data set.

As NPS constitute such a broad group of substances, with varying psychoactive effects, any conclusions on their use from our study should be drawn with caution. The associations we have demonstrated refer to NPS as a homogeneous group. While we have attempted a crude division into synthetic cannabinoid and stimulant NPS, further work should focus on investigating the NPS classes as separate entities. There is, however, an inherent problem in NPS categorisation due to the lack of accurate information regarding their constituents.

\section{Generalisability}

This study was a cross-sectional analysis of service users as opposed to a population study. The relationships we have highlighted may only apply to those who present to services, and perhaps even our local services, rather than the whole population of NPS using psychiatric patients. Equally, due to the study design, we cannot establish any causal relationships.

Our study represents a good starting point for NPS research, but more work is required. A population study is needed to appropriately characterise who is taking NPS, which NPS they are taking and what effects they are having. Routinely available testing apparatus does not test for NPS use. When, and if, this becomes available, further research will be more accurate. A better understanding of the pharmacology and effects of NPS is vital, although this is likely to be problematic, given their ever-changing nature. If we have learnt anything about NPS, it is that their synthesis will continue to outweigh attempts to control them, and psychiatric patients are likely to continue to use them. For that reason, it is essential that they become better understood, as their presence and the consequences of their use are unlikely to be diminished anytime soon.

Contributors JLS and RJL designed the study. JLS collected the data, with supervision from RJL and DVM. DVM provided supervision and advice regarding statistical methods, and SML supervised all aspects. JLS submitted 
a first draft as a student selected component project to the University of Edinburgh. All authors reviewed and commented on the final submitted paper.

Funding This research received no specific grant from any funding agency in the public, commercial or not-for-profit sectors.

Competing interests None declared.

Provenance and peer review Not commissioned; externally peer reviewed.

Data sharing statement Additional data can be accessed via the Dryad data repository at http://datadryad.org/ with the doi:10.5061/dryad.gp545.

Open Access This is an Open Access article distributed in accordance with the Creative Commons Attribution Non Commercial (CC BY-NC 4.0) license, which permits others to distribute, remix, adapt, build upon this work noncommercially, and license their derivative works on different terms, provided the original work is properly cited and the use is non-commercial. See: http:// creativecommons.org/licenses/by-nc/4.0/

\section{REFERENCES}

1. 2012/13 Scottish Crime and Justice Survey: Drug Use. 2014; Scottish Centre for Crime and Justice Research. University of Glasgow. http://www.gov.scot/Resource/0045/00453923.pdf (accessed 19 Mar 2015)

2. ACMD (Advisory Council on the Misuse of Drugs), Consideration of the Novel Psychoactive Substances ('legal highs') October 2011. https://www.gov.uk/government/uploads/system/uploads/attachment data/file/119139/acmdnps2011.pdf (accessed 18 Mar 2015).

3. Forsyth AJ. Virtually a drug scare: mephedrone and the impact of the internet on drug news transmission. Int J Drug Policy 2012;23:198-209.

4. United Nations Office on Drugs and Crime (UNODC). World Drug Report 2014. https://www.unodc.org/documents/wdr2014/World Drug_Report_2014_web.pdf (accessed 16 Mar 2015).

5. European Monitoring Centre for Drugs and Drug Addiction. European Drug Report 2012: annual report on the state of the drugs problem in Europe. 2012. http://www.emcdda.europa.eu/publications/ annual-report/2012 (accessed 16 Mar 2015).

6. United Nations Office on Drugs and Crime (UNODC). The Challenge of New Psychoactive Substances. Global SMART Programme 2013. http://www.unodc.org/documents/scientific/NPS 2013 SMART.pdf (accessed 15 Mar 2015).

7. Corazza O, Schifano F, Farre M, et al. Designer drugs on the internet: a phenomenon out-of-control? The emergence of hallucinogenic drug Bromo-Dragonfly. Curr Clin Pharmacol 2011:6:125-9.

8. Home Office. Psychoactive Substances Bill. https://www.gov.uk/ government/collections/psychoactive-substances-bill-2015 (accessed 17 Jun 2015).

9. Brandt SD, Sumnall HR, Measham F, et al. Analyses of secondgeneration 'legal highs' in the UK: Initial findings. Drug Test Anal 2010;2:377-82.

10. Peters FT, Martinez-Ramirez JA. Analytical toxicology of emerging drugs of abuse. Ther Drug Monit 2010;32:532-9.

11. Every-Palmer S. Synthetic cannabinoid JWH-018 and psychosis: an explorative study. Drug Alcohol Depend 2011;117:152-7.
12. Gibbons S. 'Legal Highs'-novel and emerging psychoactive drugs: a chemical overview for the toxicologist. Clin Toxicol 2012;50:15-24.

13. McAuley A, Hecht G, Barnsdale L, et al. Mortality related to novel psychoactive substances in Scotland, 2012: an exploratory study. Int J Drug Policy 2015;26:461-7.

14. Crawford V. Comorbidity of substance misuse and psychiatric disorders. Curr Opin Psychiatr 1996:9:231-4.

15. Martinotti G, Lupi M, Acciavatti T, et al. Novel psychoactive substances in young adults with and without psychiatric comorbidities. Bio Med Res Int 2014;2014:815424.

16. Dickey B, Azeni H. Persons with dual diagnoses of substance abuse and major mental illness: their excess costs of psychiatric care. Am J Public Health 1996;86:973-7.

17. Bartels SJ, Drake RE, Wallach MA. Long-term course of substance use disorders among patients with severe mental illness. Psychiatr Serv 1995;46:248-51.

18. Brady KT, Sinha R. Co-occurring mental and substance use disorders: the neurobiological effects of chronic stress. Focus. Am Psychiatr Publ 2007;5:229-39.

19. Lally J, Higaya EE, Nisar Z, et al. Prevalence study of head shop drug usage in mental health services. Psychiatrist 2013;37:44-8.

20. Abdulrahim D, Bowden-Jones O., on behalf of the NEPTUNE Expert Group. Guidance on the management of acute and chronic harms of club drugs and novel psychoactive substances. London: Novel Psychoactive Treatment UK Network (NEPTUNE), 2015.

21. Corazza O, Demetrovics Z, van den Brink W, et al. 'Legal highs' an inappropriate term for 'Novel Psychoactive Drugs' in drug prevention and scientific debate. Int J Drug Policy 2013;24:82-3.

22. CREW 2000. NPS at Crew Annual Report 2014-2015. 2015. https:// 1fec16444e7228ff2981-b6e25eb72df69608d37cf0f90c328ddf.ssl.cf3. rackcdn.com/2015041020-20NPS20ANNUAL20REPORT2020201520-20FINAL20-202.pdf (accessed 28 Apr 2015).

23. Westermeyer J, Walzer V. Sociopathy and drug use in a young psychiatric population. Dis Nerv Syst 1975;36:673-7.

24. Fattore L, Fratta W. Beyond THC: the new generation of cannabinoid designer drugs. Front Behav Neurosci 2011;5:60.

25. Papanti D, Schifano F, Botteon G, et al. "Spiceophrenia": a systematic overview of "Spice"-related psychopathological issues and a case report. Hum Psychopharmacol 2013;28:379-89.

26. McNabb CB, Russell BR, Caprioli D, et al. Single chemical entity legal highs: assessing the risk for long term harm. Curr Drug Abuse Rev 2012;5:304-19.

27. Salo R, Flower K, Kielstein A, et al. Psychiatric comorbidity in methamphetamine dependence. Psychiatry Res 2011;186:356-61.

28. Degenhardt L, Hall W, Lynskey M. Exploring the association between cannabis use and depression. Addiction 2003:98:1493-504.

29. Boden JM, Fergusson DM. Alcohol and depression. Addiction 2011;106:906-14.

30. Moore K, Dargan PI, Wood DM. Do novel psychoactive substances displace established club drugs, supplement them or act as drugs of initiation? The relationship between mephedrone, ecstasy and cocaine. Eur Addict Res 2013;19:276-82.

31. Arseneault L, Cannon M, Witton J, et al. Causal association between cannabis and psychosis: examination of the evidence. Br J Psychiatry 2004;184:110-17.

32. Simonato P, Corazza O, Santonastaso P, et al. Novel psychoactive substances as a novel challenge for health professionals: results from an Italian survey. Hum Psychopharmacol 2013;28:324-31. 